\title{
Influencia de la política de zonificación urbana en la localización industrial de la Ciudad de México, 1986-2014¹
}

\section{Urban zoning policy influence on industrial location of Mexico City, 1986-2014}

\author{
Fermín Alí Cruz-Muñoz*
}

\begin{abstract}
As a consequence of the neoliberal policies, the State has a passive role in urban planning. Nevertheless, in Mexico, zoning has the legal faculty to orientate industry emplacement in a city. This longitudinal and micro-spatial study analyzes the local government influence on the spatial configuration of industry in Mexico City metropolitan area. The 'laissez faire' policy is emphasized when land use regularization process is applied only in the highest production nodes. This phenomenon shows how economic force is developed as a political mechanism to transform urban planning decisions.
\end{abstract}

Keywords: industrial emplacement, zoning, metropolitan area planning, metropolitan areas, Mexico City.

\section{Resumen}

A partir de las políticas neoliberales, el Estado ha tomado una posición pasiva en la planeación urbana; no obstante, en el caso mexicano la asignación de usos de suelo todavía tiene la atribución legal de orientar la localización de la industria en las urbes. Este estudio longitudinal y microespacial analizó la capacidad del gobierno local para determinar la distribución industrial en el área metropolitana de la Ciudad de México, lo que evidenció una política de regularización legal del uso de suelo de los nodos de mayor producción. Este proceso muestra que la zonificación responde a una adecuación de la dinámica urbana, donde el gobierno reacciona ante la fuerza económica de las empresas que cuentan con mecanismos de presión política basados en su capacidad económica.

Palabras clave: localización industrial, zonificación de usos de suelo, planeamiento metropolitano, áreas metropolitanas, Ciudad de México.

\footnotetext{
${ }^{1}$ El presente trabajo forma parte del proyecto de investigación apoyado por el Conacyt titulado “Configuración de la actividad económica en la Ciudad de México” con número de registro 226250.

*Instituto Politécnico Nacional, México. Correo-e: facruzm@ipn.mx
} 


\section{Introducción}

Tradicionalmente, la distribución de las actividades industriales se ha explicado a partir de factores económicos resultado del libre desenvolvimiento del mercado. La corriente neoclásica sostiene que la mano invisible del mercado induce a las empresas a emplazar sus establecimientos para reducir sus costos de transporte y de producción (Alonso, 1960). No obstante, la capacidad del Estado para influir en la localización de la industria al interior de las ciudades no ha sido correctamente dimensionada en las teorías de distribución de la actividad económica.

Desde finales del siglo XX, con el desarrollo de las políticas neoliberales en diferentes partes del mundo, se han propiciado cambios en los procesos de planeación urbana tornándola menos restrictiva; el argumento central es que la planeación urbana pública distorsiona los mecanismos del mercado, por lo que no se alcanza la eficiencia plena de la localización de recursos en el espacio urbano, desde esta visión, el papel de la planeación urbana solamente debe corregir y evitar las fallas del mercado a partir de una regulación mínima del espacio (Gleeson y Low, 2000).

Previo a la implementación de las políticas neoliberales los Estados regulaban y ordenaban la estructura urbana de las ciudades a fin de organizar eficientemente las actividades que se realizaban en su interior. No obstante, aun cuando la planeación urbana tuvo su mayor auge en México y en específico en su ciudad capital, esta práctica gubernamental se ha visto superada por la alta dinámica que ha tenido la urbe desde la década de los setenta como resultado de la alta inmigración, así como por las cambiantes dinámicas macroeconómicas y sociopolíticas del país. No cabe duda de que la capacidad de regular la localización de la actividad urbana en la capital del país no ha sido ni suficiente ni la prioridad de los gobiernos locales.

Pareciera que desde siempre se ha estado bajo una planificación pública mínima, tal y como lo dicta la política neoliberal, esto debido a la ausencia de políticas urbanas eficientes, así como a la incapacidad técnica de las instituciones de planeación urbana para comprender las dinámicas socioeconómicas que influyen en la localización de las actividades urbanas y su dificultad para hacer cumplir los planes y programas de ordenación territorial. Incluso, ahora que se ha implementado una serie de políticas neoliberales en varias áreas, la planeación urbana se ha quedado a la zaga en cuanto a dichas reformas, mostrando una vez más la ausencia de interés por parte de Estado por construir una política neoliberal integral y específicamente en el área de la planeación urbana.

Otro de los retos mayores para la planeación de la ciudad capital es la metropolización que ha sufrido como consecuencia de su rápida expansión 
territorial. Esta cualidad ha ocasionado que los programas de desarrollo urbano no abarquen la totalidad de la urbe, generando un proceso de fragmentación de las decisiones políticas a falta de una adecuada coordinación entre las diferentes instancias del gobierno responsable. De tal manera, se tienen múltiples programas delegacionales y municipales de desarrollo que no necesariamente responden a una misma lógica de organización espacial de las actividades económicas, entre ellas, la industrial.

En este trabajo se abordará la capacidad de los gobiernos locales que conforman el Área Metropolitana de la Ciudad de México (AMCM) ${ }^{2}$ (mapa 1) en la distribución de la manufactura, a partir de la asignación de usos de suelo definidos en los diferentes planes y programas de desarrollo urbano que periódicamente tienen la facultad de realizar. Este análisis parte del principio de que los gobiernos locales tienen la facultad y obligación legal de regular el desarrollo urbano y determinar la localización adecuada de la actividad industrial. ${ }^{3}$

El estudio se realizó a partir de un análisis longitudinal desagregado para entender la correspondencia entre la localización de la actividad industrial por áreas geoestadísticas básicas (Ageb), con los distintos planes gubernamentales que definen la política de ordenamiento territorial sobre la manufactura. Derivada de esta revisión se pudo conocer la proporción de actividades manufactureras que cumplen con los lineamientos sobre

\footnotetext{
${ }^{2}$ Existen varias definiciones en relación al área metropolitana y zona metropolitana. El US Census Bureau define como área metropolitana a una ciudad central con varios suburbios adyacentes a éste con una gran interacción (Caves, 2005). Si bien no define claramente si esta área debe tener un continuo urbano, en la práctica las metropolitan statistical área (MSA) incluyen a las áreas no contiguas a la ciudad central. Una definición similar es presentada por Fuente (1999: 235) quien define al área metropolitana como una extensión urbana con varias ciudades. No obstante, otra tendencia conceptual define que la zona metropolitana es aquel territorio urbano conformado por varios municipios y que incluye a otros con cualidades urbanas que mantienen un alto grado de interacción (Inegi, 2004a: 17). En ese sentido, un área metropolitana representa el territorio urbano con continuidad espacial, descartando aquellos asentamientos periféricos dependientes de la ciudad central. Zoido et al. (2000: 225), UNESCO (1987: 1385) y la Subsecretaría de Asentamientos Humanos (s/f) definen a la metrópoli como la ciudad hegemónica de una región y que genera una alta dependencia en un área de influencia. En este trabajo, el Área Metropolitana de la Ciudad de México se entiende como esa metrópoli, por lo que se podrá usar como sinónimo de Ciudad de México, bajo el entendido que abarca toda la aglomeración urbana continua, dejando aquellos asentamientos periféricos físicamente separados pero con alta interacción con la ciudad capital.

${ }^{3}$ La zona de estudio está conformada por las 16 delegaciones y los municipios conurbados de Chalco, Valle de Chalco Solidaridad, Ixtapaluca, La Paz, Nezahualcóyotl, Ecatepec, Tlalnepantla, Coacalco, Tultitlán, Cuautitlán, Cuautitlán Izcalli, Tepotzotlán, Naucalpan, Atizapán de Zaragoza y Huixquilucan. El criterio fundamental para limitar los municipios conurbados fue su intensidad de actividad económica e industrial, y así evitar la inclusión de áreas con baja intensidad que consecuentemente sus datos no están disponibles por razones de confidencialidad, pues aunque la zona de estudio, con una superficie de $1563 \mathrm{~km}^{2}$, representa solamente $77,66 \%$ de toda el área urbana de la zona metropolitana de la Ciudad de México definida por Instituto Nacional de Estadística y Geografía (Inegi) y la Comisión Nacional de Población concentra 98,65\% de la producción industrial. La zona de estudio está conformada por 4418 Ageb, de las cuales 3317 registraron actividad manufacturera. Para mayor referencia del método de delimitación de la zona de estudio referirse a Cruz-Muñoz, 2012 (Anexo metodológico 1).
} 


\section{Mapa 1}

Área metropolitana de la Ciudad de México, territorio perteneciente a la zona de estudio

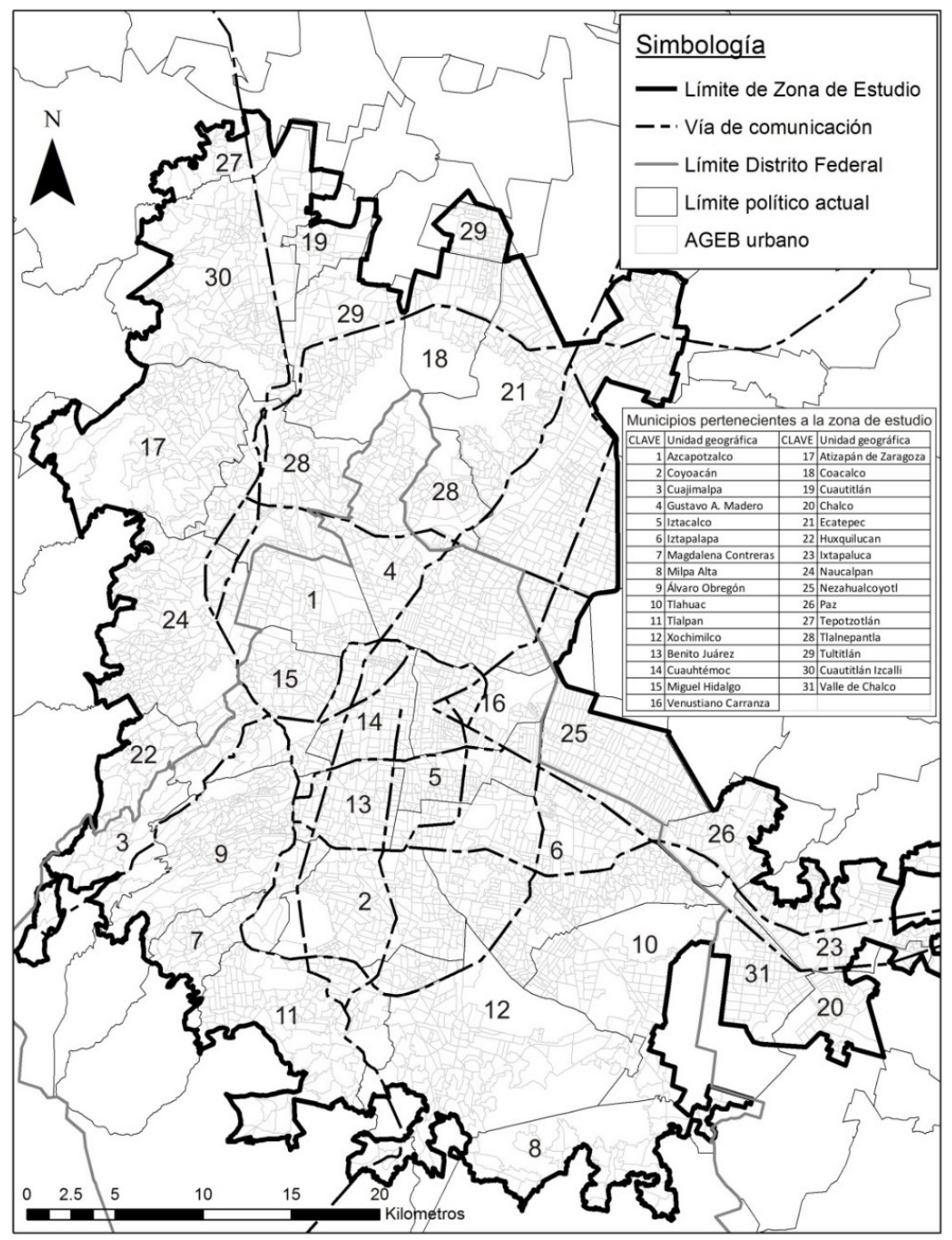

Fuente: elaboración propia con la base cartográfica de Información Referenciada Geoespacialmente Integrada en un Sistema, versión 4.0.2. (Inegi, 2004a). 
el uso de suelo y si la política pública realmente tiene injerencia en la ubicación de esta actividad o solamente sirve como un mecanismo de regularización de fábricas previamente establecidas en zonas no permitidas. Para elaborar este ejercicio analítico se retomaron los planes y programas de desarrollo urbano implementados desde mediados de la década de los ochenta hasta la actualidad, relacionándolos con la información microespacial de los Censos Industriales de 1993, 1998 y 2003 a escala de Ageb.

Los usos de suelo industrial permisibles se referenciaron geográficamente en tres tiempos. En primera instancia, se conjuntaron los planes delegacionales de desarrollo urbano aprobados en 1986 y los planes estratégicos de centro de población de los municipios conurbados de 1984. Para el segundo corte temporal se localizaron los polígonos de los usos de suelo industrial permisibles, según los programas de desarrollo urbano delegacionales y planes municipales de desarrollo urbano vigentes para 1997. Y por último, se concentraron los planes y programas vigentes hasta 2014. La comparativa entre la actividad manufacturera con los polígonos autorizados para el uso industrial se logró mediante una sobreposición espacial, apoyándose en un sistema de información geográfica que brindó la posibilidad de obtener datos más exactos en la comparación.

Cabe mencionar que este ejercicio tiene sus limitaciones debido al nivel de agregación de la información. Es decir, los usos de suelo manufactureros asignados no corresponden con los límites de las Ageb, por lo que cuando áreas con actividad económica se traslaparon con el uso industrial permisible se supuso que dicha actividad se estaba realizando al interior de esa área autorizada. Adicionalmente, se han descartado zonas industriales permisibles que se encuentran fuera de la zona urbana, pese a estar dentro de la zona de estudio, ya que no se tiene información censal para realizar la comparación. Otra limitación es que no se consideró el uso mixto, donde también es permitido realizar muy limitados tipos de actividad industrial debido a la presencia de áreas habitacionales.

\section{Planeación urbana en el contexto neoliberal}

Como resultado del neoliberalismo se han retomado diversos enfoques teóricos sobre el proceso de urbanización y el papel del Estado minimalista como planificador. Bajo el enfoque del Estado benefactor se afirmaba que mediante una planeación adecuada y guiada por una agencia pública era posible solucionar los problemas provocados por el crecimiento demográfico, la industrialización y el desarrollo tecnológico y científico (Webster, 1958). Actualmente se argumenta que son peores las fallas del Estado que las del mercado, por lo que las políticas neoliberales se 
orientan hacia la liberalización de las fuerzas del mercado como mecanismos de regulación de la organización de las actividades urbanas, incluyendo la industrial, cuya lógica de localización ha sido objeto de estudio por las teorías neoclásicas plasmadas por la nueva economía urbana.

\subsection{Zoning en el contexto neoliberal}

En el contexto de la planeación urbana, la asignación de usos de suelo permitidos ha sido una herramienta de localización de la actividad urbana en todas las latitudes. Con su origen en Estados Unidos a inicios de la década de los veinte del siglo XX, la zonificación (zoning) ha sido la vía por la que se ha conservado la homogeneidad de zonas habitacionales (Babcock, 1995).

El espíritu original de la asignación de usos de suelo fue crear un mecanismo para maximizar el valor de las propiedades, por lo que la zonificación debía ser determinada por las fuerzas de mercado. Bajo este enfoque, dicha zonificación permitiría que cada propiedad pudiera usarse de tal manera que asegurara que la suma de todas las propiedades alcanzara el máximo valor guiado por las fuerzas del mercado inmobiliario. Por lo tanto, cada propiedad debería usarse de tal forma que obtuviera el mayor valor, tanto comercial como de uso, sin perjudicar el valor de otras propiedades (Babcock, 1995).

La asignación del uso de suelo permitido debe proteger al mercado de las imperfecciones de las operaciones inmobiliarias de oferta y demanda. Es decir, la interferencia del planificador a través de la designación de uso de suelo debe realizarse solamente cuando la interacción de actividades entre dos o más terrenos afecte negativamente el valor de algún predio. Bajo esta óptica, la asignación del uso de suelo se va adaptando históricamente a las dinámicas que el mercado dicta, formando una zonificación "óptima” al interior de las áreas urbanas.

Es interesante comentar que esta herramienta de planeación, pese a haber sido creada bajo el contexto de las políticas liberales capitalistas, fue altamente utilizada por las instituciones públicas de planeación urbana durante el periodo de Estado benefactor. Durante esa etapa, se argumentaba que el Estado debía asumir un papel proactivo en la organización espacial de las actividades industriales para promover las mejores condiciones del proceso general de producción, que a su vez contribuirían a la administración y operación eficiente de las actividades empresariales en particular (Webster, 1958). Bajo este enfoque, la implementación de políticas de ordenamiento es inicialmente más factible para el gobierno, pues tiene la posibilidad de observar el panorama general de la estructura urbana; es decir, "la planeación, promoción y conducción del desarrollo 
urbano es una función pública, ya que es el Estado el único con capacidad jurídica, política y técnica y con legitimidad, para llevar a cabo esta tarea” (Iracheta, 1997: 199).

Décadas más tarde, la política neoliberal ha retomado los principios originales de la zonificación para incorporarlos en los cambios estructurales de las funciones del Estado y su papel como planificador urbano. De tal forma, la zonificación debe prevenir los efectos negativos asociados con la proximidad de actividades incompatibles (Sager, 2011). Por lo tanto, la zonificación debe dejar de ser una restricción excesiva hacia la libertad del privado para el uso de su propiedad. Esta política ha generado que los gobiernos asuman un papel reactivo, donde solamente responden cuando grupos sociales de presión o empresarios con gran poder económico utilizan su fuerza financiera como mecanismo de presión política. Por ello, ahora estos sectores de la población dominan las relaciones público-privadas, especialmente en temas relacionados con el desarrollo económico y físico (Feagin, 1990).

Bajo esta óptica neoliberal, diversas ciudades han modificado sus procesos de planeación urbana pública, en estos procesos, la zonificación de la ciudad, a través de usos de suelo restrictivos, se ha modificado hacia nuevos polígonos de actuación de participación público-privada. Legislaciones como la de Kosovo (Goxha, 2014), Gran Bretańa (Peel et al., 2009), Nueva Zelanda (Gleeson y Grundy, 1997) y China (Li y Tiyan, 2011, y Yuan et al., 2008) se han modificado, permitiendo que el sector inmobiliario asuma el control de la organización de la actividad urbana, con lo que desaparece el tradicional uso de la zonificación.

\subsection{Ineficaz planeación urbana mexicana}

En la legislación mexicana, el propósito de la asignación de usos de suelo siempre ha estado bajo la perspectiva del Estado intervencionista, donde éste tomaría una actitud positiva hacia la promoción del bienestar general, aun cuando esto significara la intervención en la vida económica. Bajo esta teoría, el papel del gobierno no se limita a conservar la gobernanza y prevenir el desorden, sino también a tomar medidas para guiar a los ciudadanos al desarrollo de un ambiente en el que puedan vivir; para ello sería necesaria una distribución justa de los recursos y el gobierno requeriría tener el poder para eliminar las inequidades económicas, resultado de una competencia sin restricciones.

Esta postura se sustentaba bajo el postulado de que el espacio urbano, como cualquier fuerza productiva, debe mejorarse mediante acciones que no siempre es factible que realicen el sector privado. La organización espacial de las actividades en el interior de la ciudad se logra bajo un Estado 
de derecho donde el gobierno define y otorga obligatoriedad a las leyes que emite y que están relacionadas con dicha organización espacial.

No obstante la capacidad del gobierno mexicano para lograr un desarrollo urbano adecuado y ordenado se ha visto históricamente superado por el rápido proceso de urbanización. La explosión demográfica, en combinación con la migración de las zonas rurales hacia la ciudad, en especial hacia la capital del país, originó una demanda de vivienda y suelo que superó la capacidad gubernamental para satisfacerla.

Actualmente, ante la política neoliberal, es posible ratificar la ausencia de interés por parte del gobierno mexicano por construir desde las bases legales un sistema de planeación adecuado a los nuevos requerimientos de las ciudades; pese a los cambios estructurales en diversas áreas de la vida política mexicana, el cuerpo normativo sigue con los postulados de mediados del siglo XX, sin proyección a ser adecuados para la nueva visión neoliberal.

\section{Ordenamiento industrial en el AMCM a través del uso de suelo}

Los antecedentes de la asignación del uso de suelo de la industria en la Ciudad de México vienen con el primer plano regulador para dicha demarcación, en este plano, realizado por el arquitecto Contreras en 1933, se determinó la conformación de la zona industrial Vallejo en Azcapotzalco, así como dos zonas más: la antes delegación Guadalupe Hidalgo, hoy Gustavo A. Madero, y al poniente del derecho de vía del Ferrocarril Central, en el Distrito Central. Ya en 1936, en el reglamento de la Ley de Planificación y Zonificación del Distrito Federal se establecían 11 zonas industriales y cinco zonas más fueron creadas ańos posteriores, a fin de ordenar la anárquica distribución industrial en la Ciudad de México (Sánchez, 1999). Es posible observar cómo, desde ese momento, los planes eran rebasados por la dinámica industrial.

La política de regularización de las actividades urbanas rápidamente sustituyó el objetivo central de regular territorialmente y ordenar la ciudad a través de la asignación del uso de suelo (Cruz-Muñoz, 2012). La creación del conjunto de leyes encabezadas por la Ley General de Asentamientos Humanos, que fomentaron la elaboración de planes y programas de desarrollo urbano tanto de carácter metropolitano como municipales y delegacionales, no significó que la organización espacial de la actividad industrial al interior de la ciudad fuese producto de un proceso planeado y racional.

A partir de ese momento, se tiene la percepción que la planeación urbana siempre ha estado a la zaga de los fenómenos urbanos que modifican la dinámica intraurbana e interurbana y que transforman la estruc- 
tura de la ciudad. Esta condición se manifiesta en la organización de la industria, donde pese a que los programas de desarrollo urbano definen las zonas urbanas permisibles para realizar actividades manufactureras, nos enfrentamos a una normatividad que Garza (1998) denomina virtual, ya que el gran número de leyes, reglamentos, programas, declaratorias y bandos no son verdaderamente atendidos. Sin embargo, no existe evidencia empírica a escala intrametropolitana que analice lo que la población en general de manera intuitiva deduce, esto es, el cuerpo jurídico-legal relacionado con la localización industrial no es plenamente respetado.

\subsection{Evolución de la asignación del uso de suelo industrial, 1986-2014}

En el Distrito Federal, los programas delegacionales de desarrollo urbano asignan cada vez menos superficie de suelo para el uso industrial, reduciéndose el área de 2410 a 1365, hectáreas de 1986 a la actualidad. A nivel metropolitano se observa un constante incremento del área autorizada para la actividad manufacturera, pese al proceso de desindustrialización del AMCM y de la política de descentralización de la industria implementada por el Plan Nacional de Desarrollo aprobado en 1983, el cual tenía el objetivo de abatir los problemas de contaminación atmosférica y reducir el alto consumo de recursos energéticos y agua que ya ocasionaban problemas de escasez en la ciudad (Dirección General de Reordenación Urbana y Protección Ecológica, 1987).

Esta política de descentralización industrial fue aprovechada por los gobiernos de los municipios conurbados para atraer inversión manufacturera, lo cual se manifestó en los nuevos usos industriales asignados en los planes urbanos elaborados en 1997. La proporción del uso de suelo industrial permisible de la ciudad se incrementaría aún más en dichos municipios, pues las áreas para dicho uso en municipios conurbados pasó de 61,26\% en 1986 a 77,67\% en la actualidad (cuadro 1).

Debido a la fragmentación territorial de la política de descentralización industrial, donde las líneas de acción se limitaban al Distrito Federal, no se logró el objetivo de trasladar la industria de la capital nacional al resto del país. La promoción para la apertura de unidades económicas en municipios conurbados no abatió los problemas de contaminación atmosférica y consumo de recursos en la ciudad. La instalación de establecimientos manufactureros en estas demarcaciones no redujo los niveles de contaminación debido a que se encontraban al interior de la Cuenca de México. Algo similar sucedio con el abastecimiento de energía eléctrica y de agua, pues los municipios conurbados con la Ciudad de México compartían los mismos sistemas de distribución de dichos servicios. 


\section{Cuadro 1 \\ Área Metropolitana de la Ciudad de México, superficie de suelo industrial permitido por unidad administrativa, 1986, 1997 y 2014 (hectáreas)}

\begin{tabular}{|c|c|c|c|c|c|c|}
\hline \multirow[b]{2}{*}{ Demarcación } & \multicolumn{2}{|c|}{1986} & \multicolumn{2}{|c|}{1997} & \multicolumn{2}{|c|}{2014 (vigente) } \\
\hline & Superficie & $\%$ & Superficie & $\%$ & Superficie & $\%$ \\
\hline Ciudad de México & $4,156,00$ & 100,00 & $5,727,55$ & 100,00 & $6,112,96$ & 100,00 \\
\hline Distrito Federal & $2,410,09$ & 38,74 & $1,539,24$ & 26,87 & $1,365,05$ & 22,33 \\
\hline Azcapotzalco & 683,78 & 10,99 & 700,84 & 12,24 & 662,84 & 10,84 \\
\hline Coyoacán & 96,31 & 1,55 & 36,73 & 0,64 & 36,73 & 0,60 \\
\hline Cuajimalpa & 99,62 & 1,60 & 0,00 & 0,00 & 0,00 & 0,00 \\
\hline Gustavo A. Madero & 437,41 & 7,03 & 336,88 & 5,88 & 336,88 & 5,51 \\
\hline Iztacalco & 12,51 & 0,20 & 14,10 & 0,25 & 98,69 & 1,61 \\
\hline Iztapalapa & 365,52 & 5,87 & 241,34 & 4,21 & 138,36 & 2,26 \\
\hline Magdalena Contreras & 0,00 & 0,00 & 0,00 & 0,00 & 0,00 & 0,00 \\
\hline Milpa Alta & 0,00 & 0,00 & 0,00 & 0,00 & 0,00 & 0,00 \\
\hline Álvaro Obregón & 230,53 & 3,71 & 50,26 & 0,88 & 50,26 & 0,82 \\
\hline Tláhuac & 0,00 & 0,00 & 0,00 & 0,00 & 0,00 & 0,00 \\
\hline Tlalpan & 14,13 & 0,23 & 25,64 & 0,45 & 25,64 & 0,42 \\
\hline Xochimilco & 28,14 & 0,45 & 4,22 & 0,07 & 0,00 & 0,00 \\
\hline Benito Juárez & 31,30 & 0,50 & 15,22 & 0,27 & 0,00 & 0,00 \\
\hline Cuauhtémoc & 0,00 & 0,00 & 0,00 & 0,00 & 0,00 & 0,00 \\
\hline Miguel Hidalgo & 353,54 & 5,68 & 53,82 & 0,94 & 0,00 & 0,00 \\
\hline Venustiano Carranza & 57,30 & 0,92 & 60,19 & 1,05 & 15,65 & 0,26 \\
\hline Municipios conurbados & $1,745,92$ & 61,26 & $4,188,31$ & 73,13 & $4,747,90$ & 77,67 \\
\hline Atizapán de Zaragoza & 40,00 & 0,64 & 36,18 & 0,63 & 119,44 & 1,95 \\
\hline Coacalco & 0,00 & 0,00 & 17,62 & 0,31 & 19,39 & 0,32 \\
\hline Cuautitlán & 0,00 & 0,00 & 0,00 & 0,00 & 144,22 & 2,36 \\
\hline Chalco & 0,00 & 0,00 & 6,42 & 0,11 & 105,44 & 1,72 \\
\hline Ecatepec & 983,80 & 15,81 & 652,06 & 11,38 & 547,00 & 8,95 \\
\hline Huixquilucan & 0,00 & 0,00 & 0,00 & 0,00 & 0,00 & 0,00 \\
\hline Ixtapaluca & 221,75 & 3,56 & 133,13 & 2,32 & 122,71 & 2,01 \\
\hline Naucalpan & 623,90 & 10,03 & 50,26 & 0,88 & 393,08 & 6,43 \\
\hline Nezahualcóyotl & 0,00 & 0,00 & 24,22 & 0,42 & 24,22 & 0,40 \\
\hline $\mathrm{La} \mathrm{Paz}$ & 436,28 & 7,01 & 246,85 & 4,31 & 379,09 & 6,20 \\
\hline Tepotzotlán & 71,71 & 1,15 & 74,57 & 1,30 & 199,31 & 3,26 \\
\hline Tlalnepantla de Baz & $1,042,00$ & 16,75 & $1,283,09$ & 22,40 & 744,26 & 12,18 \\
\hline Tultitlán & 392,28 & 6,30 & 335,53 & 5,86 & 739,18 & 12,09 \\
\hline Cuautitlán Izcalli & $*$ & - & $1,328,38$ & 23,19 & $1,210,55$ & 19,80 \\
\hline Valle de Chalco & $*$ & - & 0,00 & 0,00 & 0,00 & 0,00 \\
\hline
\end{tabular}

* Los municipios de Cuautitlán Izcalli y Valle de Chalco todavía no habían sido creados en 1986, pertenecían a las demarcaciones de Cuautitlán y Chalco, respectivamente.

Fuente: elaboración propia con base en los planes y programas locales de desarrollo urbano aprobados entre 1984 y 2009. (Secretaría de Desarrollo Urbano, del Estado de México 2003-2003d; 2008 y Secretaría de Desarrollo Urbano y Vivienda, 1996). 


\section{Mapa 2}

Área Metropolitana de la Ciudad de México, localización del uso de suelo industrial permitido, 1986

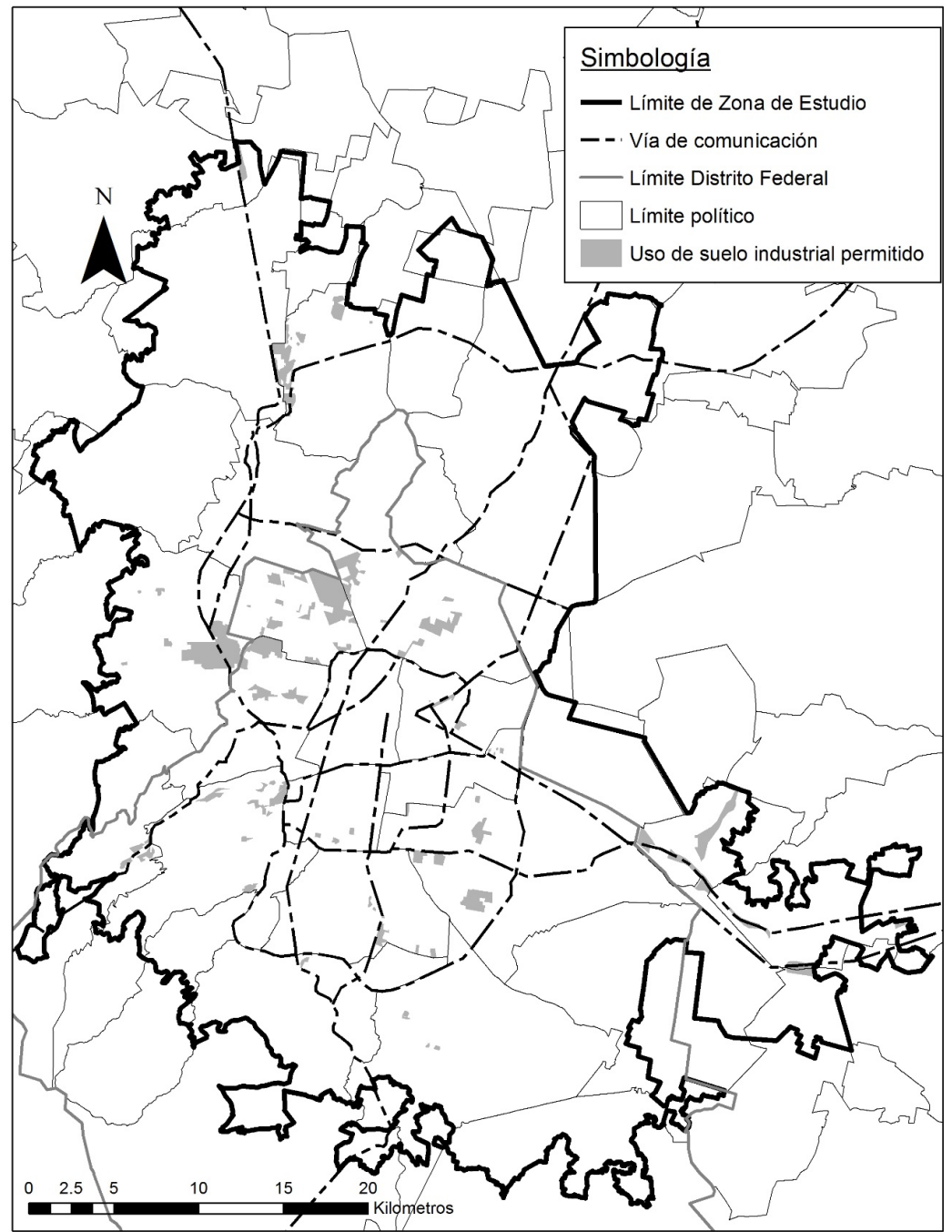

Fuente: elaboración propia con base en Garza (1987) y Gobierno del Estado de México (1984-1984h, 1985 y 1985 a). 
No obstante, los cambios en la asignación de suelo industrial influyeron en la localización industrial y promovieron su emplazamiento en la periferia urbana. La planeación metropolitana de mediados de la década de los ochenta asignó principalmente el suelo destinado para la industria en los municipios conurbados del norte: Tlalnepantla de Baz y Ecatepec, junto con Azcapotzalco, delegación que históricamente ha concentrado la industria fabril en la ciudad (mapa 2$) ;^{4}$ estos territorios agrupaban $16,75 \%, 15,81 \%$ y $10,99 \%$, respectivamente, del total del suelo destinado para esta actividad. Estas proporciones las posicionaban como las primeras tres demarcaciones con mayor superficie asignada para el uso manufacturero, concentrando $43,55 \%$ del total del uso de suelo industrial permitido (cuadro 1).

En 1997 existió un desplazamiento de la asignación de suelo industrial hacia municipios conurbados del norte de la ciudad. Este proceso, como se puede observar en el mapa 3, se desarrolló a lo largo de las principales vías regionales, especialmente las carreteras que se comunican hacia Querétaro y, en menor medida, hacia Pachuca. Este fenómeno contrasta con la política del Programa de desarrollo urbano del Distrito Federal de 1996, que pretendía disminuir la alta especialización del suelo urbano para disminuir los largos desplazamientos laborales. Este intento por alcanzar una distribución más equilibrada del uso de suelo se vio obstaculizada por lo dispuesto en los planes municipales de desarrollo urbano de las demarcaciones conurbadas al concentrar $57 \%$ del uso industrial permisible del área metropolitana, especialmente en Tlalnepantla, Cuautitlán Izcalli y Ecatepec. ${ }^{5}$

Actualmente, se puede observar que los planes y programas vigentes favorecen la localización de la actividad industrial en los municipios periféricos de la ciudad, especialmente a lo largo de la carretera y autopista a Querétaro. Esta tendencia ocasiona que 44\% del uso de suelo destinado para la manufactura se concentre en Tlalnepantla, Cuautitlán Izcalli y Tultitlán. Cabe mencionar que la promoción del desarrollo industrial a través de la asignación del uso de suelo disminuye en el municipio de Ecatepec, asignando para esta actividad solamente zonas cercanas a sus límites con el Distrito Federal (mapa 4).

\footnotetext{
${ }^{4}$ La delegación se ha caracterizado por ser siempre un importante nodo industrial a nivel metropolitano, desde la creación de la Zona Industrial Vallejo en 1944 hasta la actualidad. Para mayor referencia de la evolución histórica de las zonas industriales en el área metropolitana de la Ciudad de México se recomienda revisar a Cruz-Muńoz y Garza (2014). Actualmente, la zona industrial de Vallejo se clasifica como el principal centro industrial a nivel nacional según generación de empleos formales directos (Real Estate, Market \& Lifesyle, 2012).

${ }^{5}$ Cabe mencionar que parte de esta tendencia de localización periférica por parte de la actividad manufacturera responde a una serie de factores económicos que reducen costos de producción como el bajo valor del suelo y proximidad a vías regionales de comunicación.
} 


\section{Mapa 3}

Área Metropolitana de la Ciudad de México, localización del uso de suelo industrial permitido, 1997

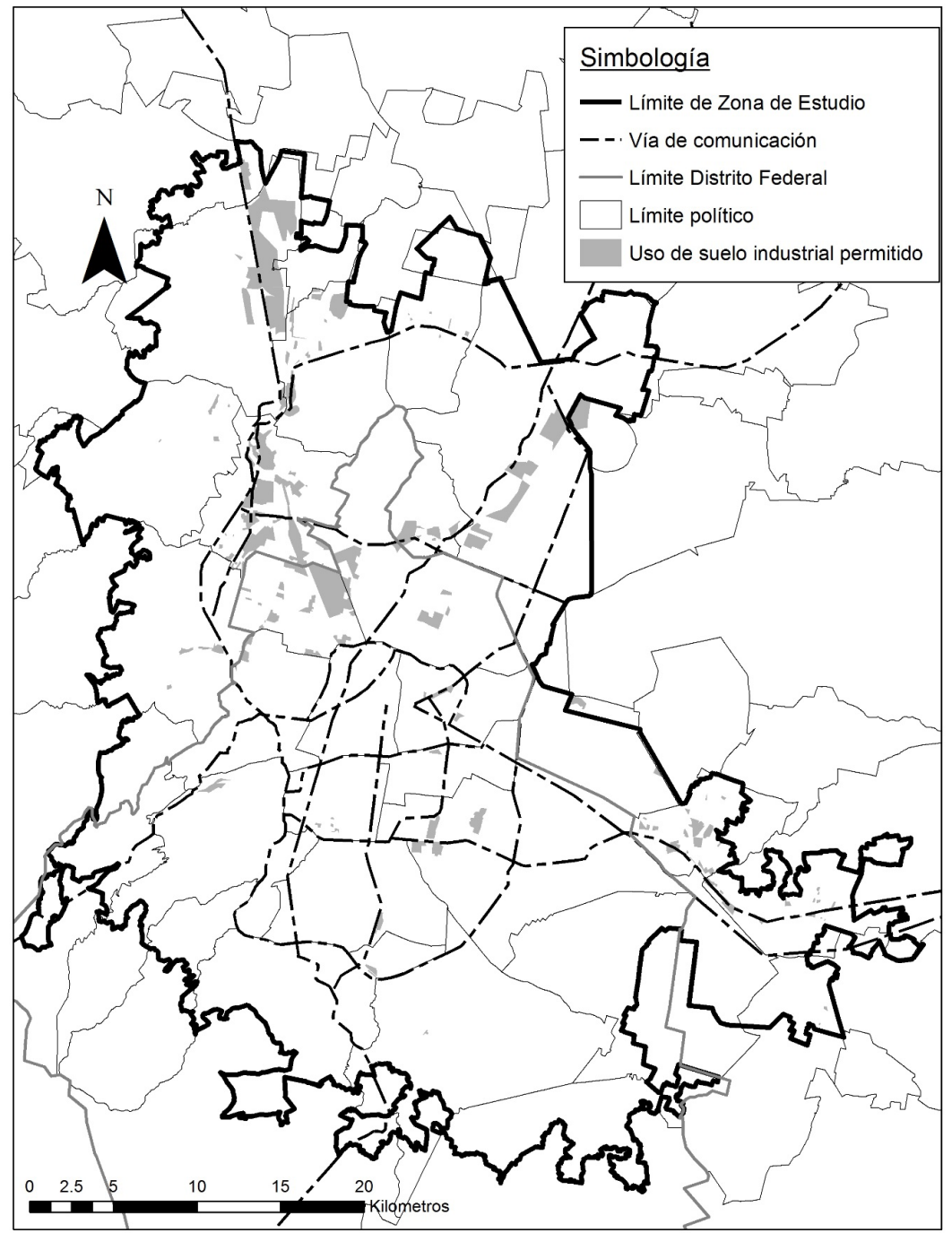

Fuente: elaboración propia con base en el Gobierno del Distrito Federal (1997-1997o) y Garza (2000). 


\section{Mapa 4}

Área Metropolitana de la Ciudad de México, localización del uso de suelo industrial permitido, 2014 (vigentes)

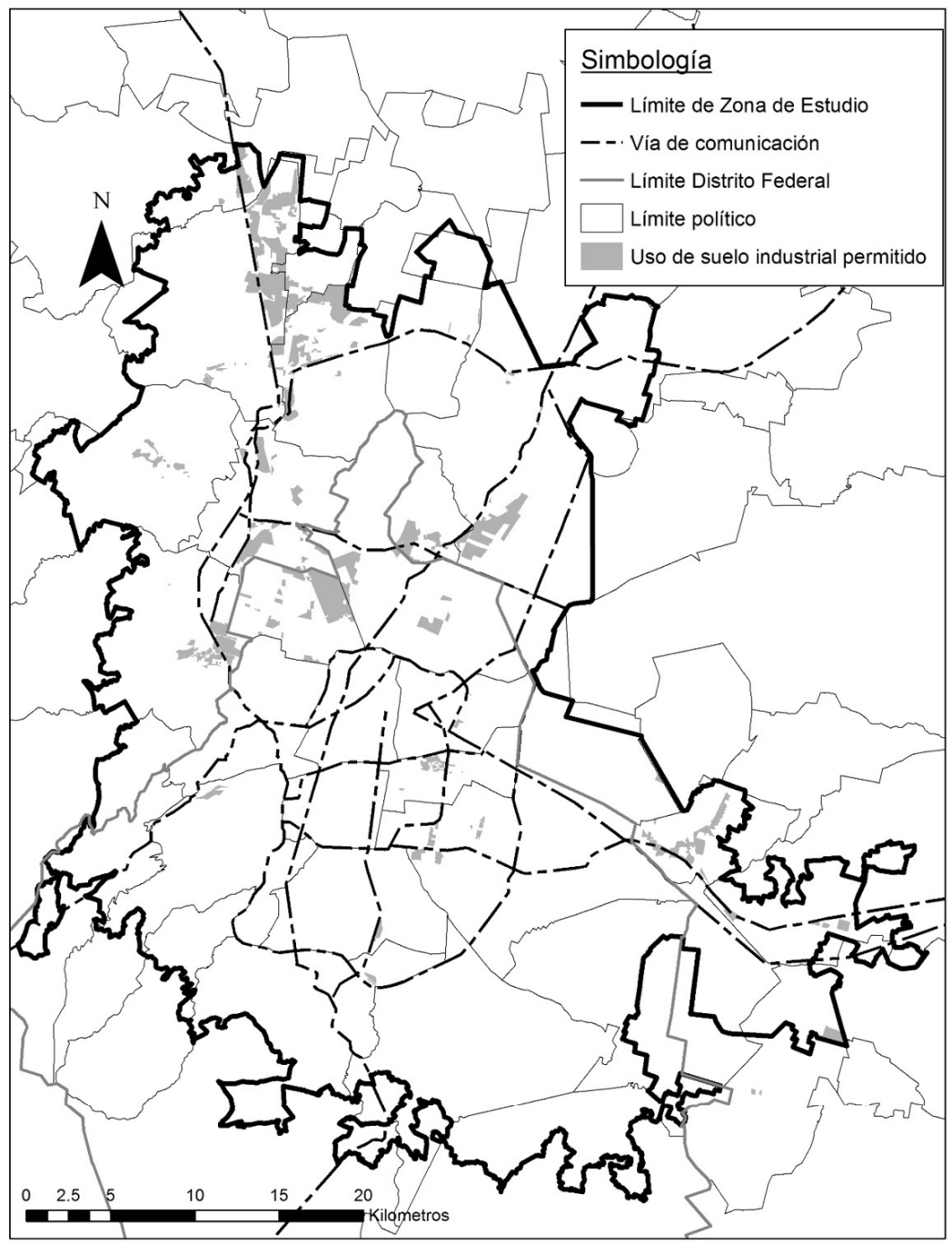

Fuente: elaboración propia con base en Gobierno del Distrito Federal (2005-2005c; 2008-2008e) y de Secretaría de Desarrollo Urbano del Estado de México (2003-2003c, 2004, 2004a, 2005, 2005a, 2007, 2008 y 2009-2009c). 
A pesar de la clara disminución de suelo destinado para la industria en el Distrito Federal, cabe resaltar que las delegaciones que originalmente concentraban la mayor cantidad de suelo autorizado para la manufactura, Azcapotzalco y Gustavo A. Madero, han mantenido la superficie asignada a la industria. Sin embargo, su participación a nivel metropolitano ha caído drásticamente a causa del incremento del uso de suelo permisible en los municipios conurbados.

\subsection{Localización manufacturera versus usos de suelo industrial permisible}

Al comparar la distribución de las unidades económicas mostrada en el mapa 5 con los programas normativos vigentes a mediados de la década del ochenta (mapa 2) es evidente la discordancia entre ellos; se evidencia la falta de capacidad para regular esta actividad al interior del AMCM.

Como se puede observar, casi todos los municipios y delegaciones tienen actividad manufacturera dispersa, por lo que no se encuentran únicamente en las zonas permisibles. Destacan especialmente las delegaciones de Venustiano Carranza y Coyoacán, y los municipios de Chalco, Cuautitlán Izcalli, Ixtapaluca y Ecatepec que muestran una concentración de actividad industrial evidente en zonas no asignadas para dicho uso. Solamente en pocos municipios se observa mayor coincidencia entre las zonas con uso de suelo industrial y Ageb con actividad manufacturera. Al observar el mapa 5 y compararlo con el mapa 2 se puede observar que en la delegación Álvaro Obregón y en los municipios de Naucalpan, La Paz, Tultitlán y Tepotzotlán, las áreas tienen mayor concordancia.

En referencia a las cualidades de los establecimientos que se encontraban dentro o fuera de los polígonos asignados para el uso industrial, en el cuadro 2 se muestra la proporción de Ageb con actividad industrial en 1993 que se emplazan total o parcialmente en zonas autorizadas para dicho uso, según los planes y programas elaborados entre 1984 y 1986. En el AMCM, 3317 áreas registraron actividad industrial; 92\% de estas áreas no se encontraron dentro de las zonas industriales definidas por los gobiernos locales. Como resultado, de los 18,565 establecimientos industriales, $86 \%$ se localizaban en zonas con uso diferente y menos de $14 \%$ de las unidades económicas estaban en áreas legalmente establecidas.

La gran proporción de unidades económicas emplazadas fuera de los polígonos con asignación de uso industrial no se expresa en cuanto a personal ocupado y producción se refiere, mostrando una heterogeneidad entre los establecimientos ubicados dentro y fuera de los polígonos industriales autorizados. Casi $40 \%$ de los trabajadores empleados en el sector se concentra en las zonas permitidas. En cuanto a la producción 


\section{Mapa 5}

Área Metropolitana de la Ciudad de México, distribución microespacial de unidades económicas del sector industrial manufacturero, 1993

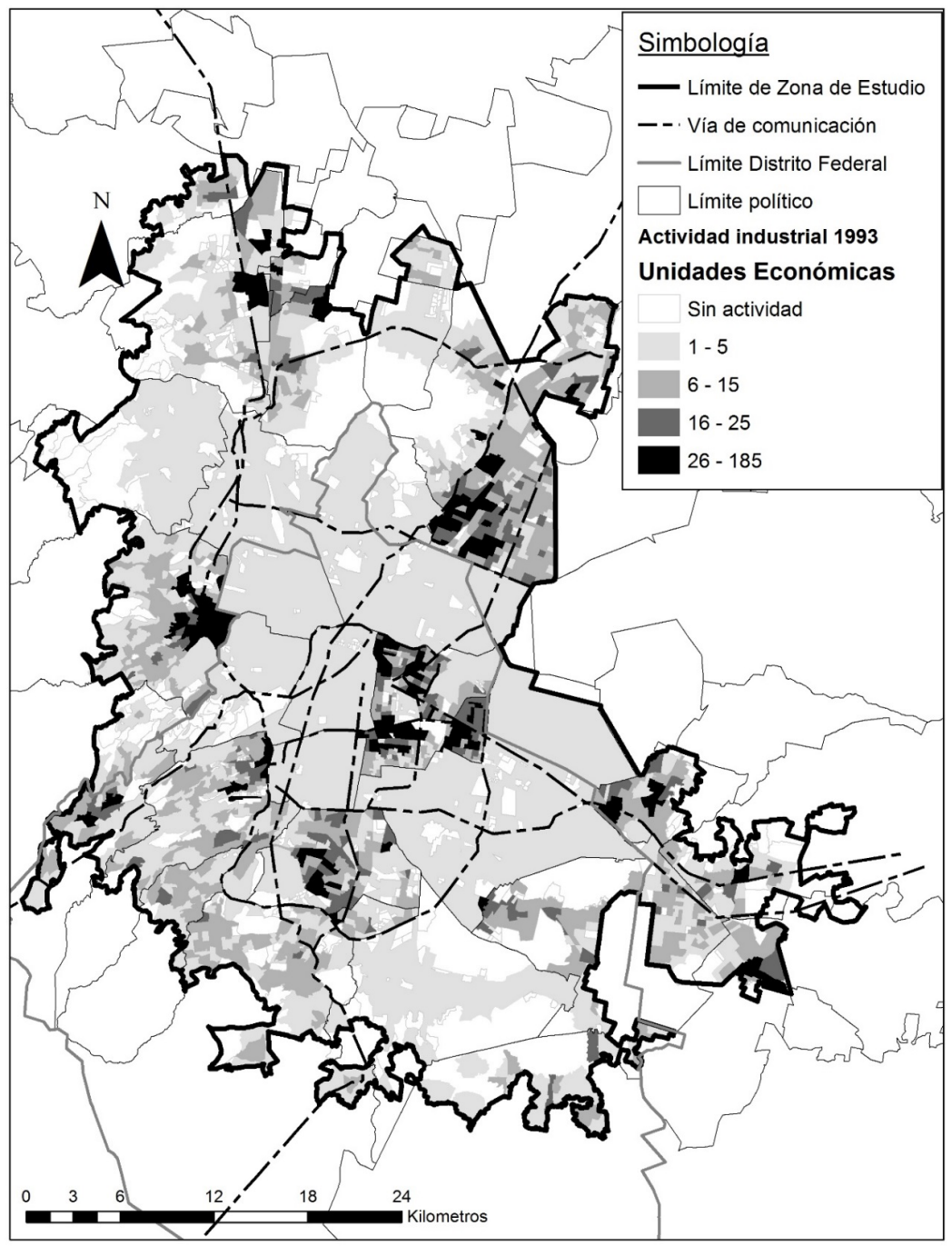

Fuente: elaboración propia con base en los datos del XIV censo industrial, 1994 (Inegi, 1994). 


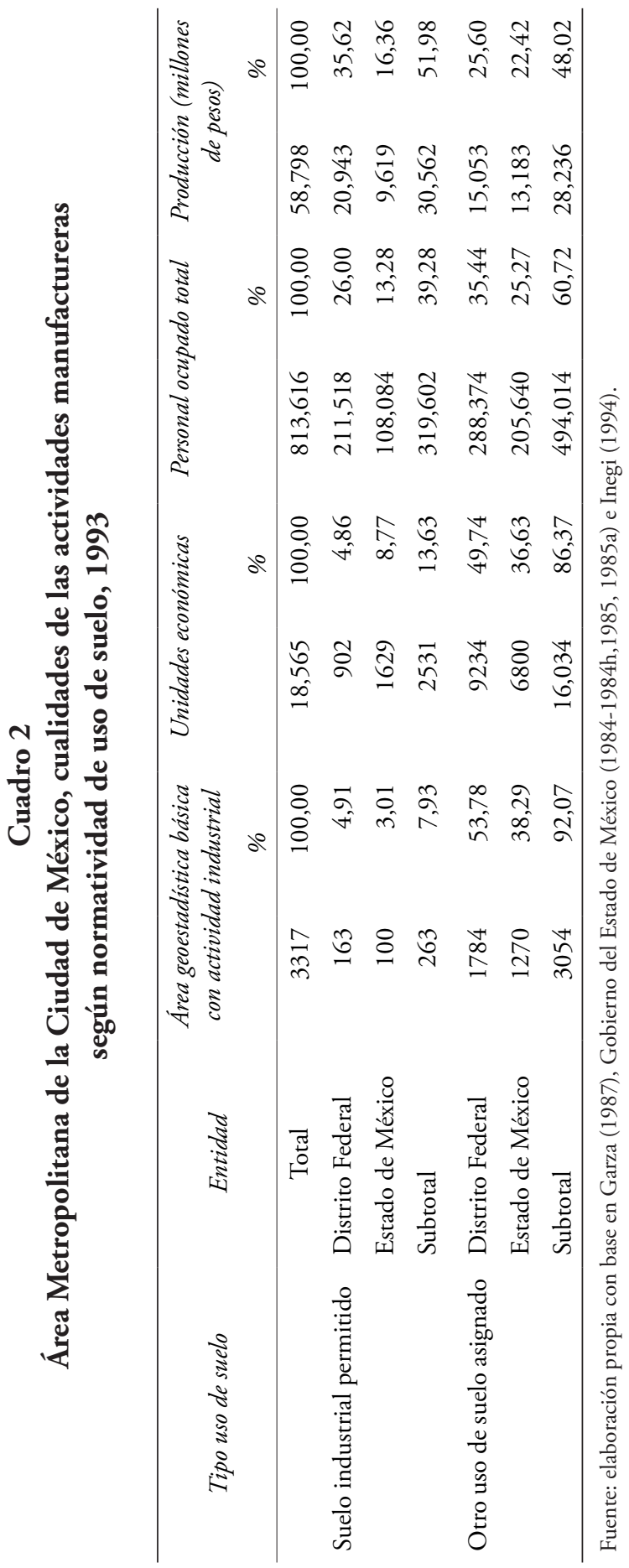


manufacturera, cabe destacar que la mayoría, $52 \%$, se localiza en las 263 Ageb asignadas para el uso industrial (cuadro 2).

Esta información revela que si bien gran cantidad de establecimientos industriales se encontraban dispersos en toda el AMCM, las 2531 unidades económicas emplazadas dentro de las Ageb con suelo asignado para la actividad industrial concentraban la mayoría de la producción. Por lo que se puede deducir que las empresas industriales más importantes en cuanto a productividad se localizaban en zonas donde existe una certeza jurídica de uso de suelo. La producción anual por establecimiento en suelo permitido industrial alcanzó más de 12 millones de pesos, mientras que las unidades económicas encontradas fuera de las zonas industriales autorizadas solamente tenían una producción de 1,700,000 pesos en promedio.

Las empresas emplazadas en suelo industrial tienden a emplear mayor personal que aquéllas que están en zonas no autorizadas. Las empresas que se encontraban en suelo asignado para uso industrial promediaban 126 trabajadores por unidad económica, mientras que aquellas fuera de estas zonas apenas alcanzaron 30 empleados por establecimiento.

Cabe resaltar que las empresas localizadas en suelo industrial permisible en el Distrito Federal son las que hacen más contrastantes las diferencias mencionadas previamente. Estas unidades industriales alcanzan una producción por establecimiento de más $23,200,000$ pesos corrientes y en promedio emplean a más de 234 empleados por fábrica. Mientras que las empresas en los municipios conurbados ubicadas en los polígonos con uso industrial tienen una producción y trabajadores por unidad económica de solamente 5,900,000 pesos y 66 empleados. Esto puede estar relacionado con la antigüedad de las empresas, lo que lleva a una mayor consolidación como negocio favorecido además por la certidumbre jurídica que brinda la autorización de suelo industrial.

Posteriormente, se revisó la distribución de la actividad manufacturera de 2003, mostrada en el mapa 6 y se comparó con la localización de las zonas industriales asignadas por los gobiernos locales descritas en el mapa 3. El nivel de inconsistencias entre localización real y permitida de la actividad no sufre importantes cambios: existen delegaciones como Cuauhtémoc, Coyoacán e Iztapalapa y municipios como Nezahualcóyotl, Ixtapaluca y Chalco con Ageb de alta concentración de establecimientos industriales en zonas designadas para otros usos, tales como habitacionales mixtos o habitacionales con comercio, principalmente. Cabe mencionar que nuevamente se encontraron demarcaciones como Azcapotzalco, Cuautitlán Izcalli, Tlalnepantla y Ecatepec que en sus zonas industriales autorizadas se concentran las Ageb con mayor cantidad de establecimientos. 


\section{Mapa 6}

Área Metropolitana de la Ciudad de México, distribución microespacial de unidades económicas del sector industrial manufacturero, 2003

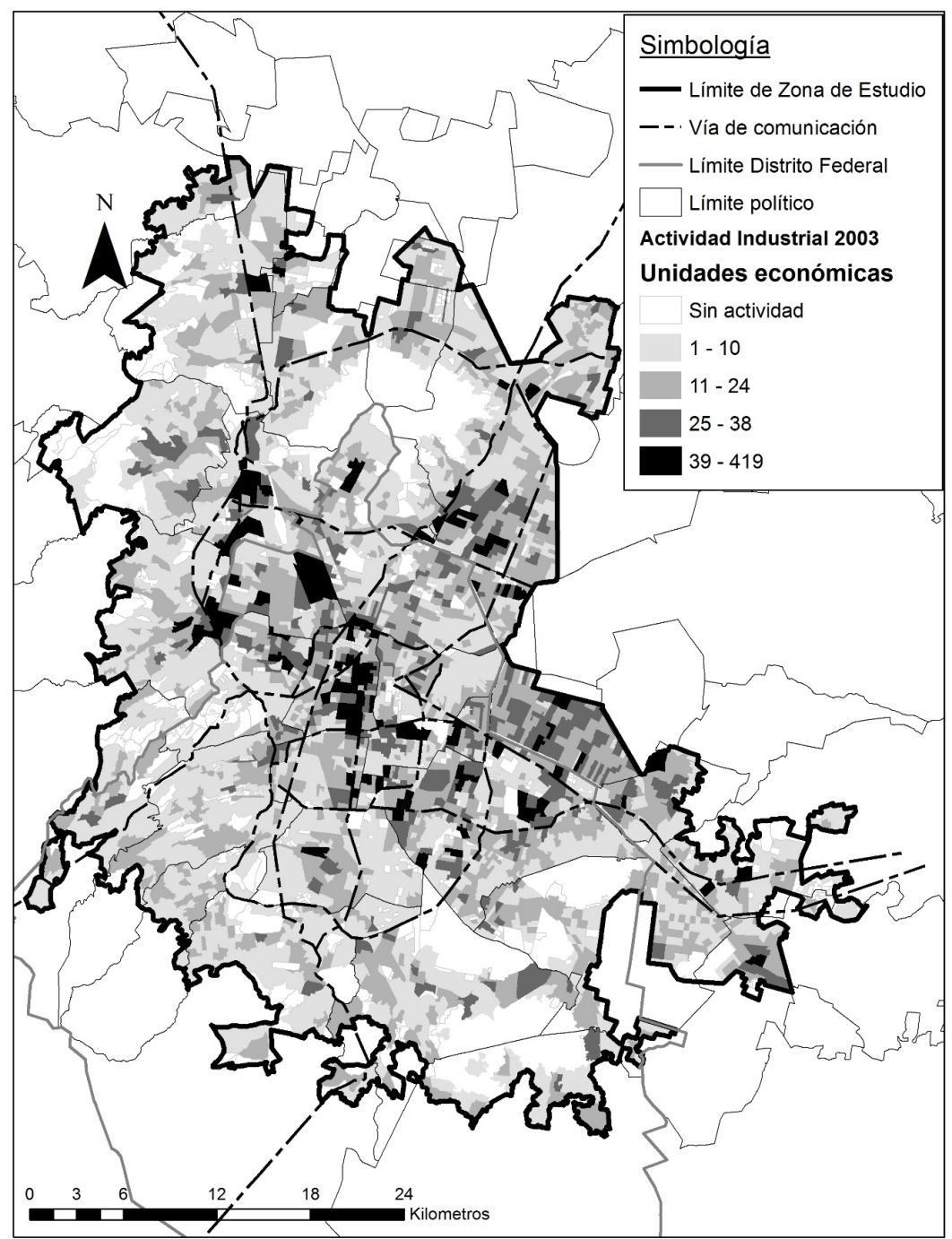

Fuente: elaboración propia con base en los datos del XIV Censo Industrial, 1994 y XVI Censo industrial, 2004 (Inegi, 1994 y 2004). 
Posteriormente, se revisó la distribución de la actividad manufacturera de 2003, mostrada en el mapa 6 y se comparó con la localización de las zonas industriales asignadas por los gobiernos locales descritas en el mapa 3. El nivel de inconsistencias entre localización real y permitida de la actividad no sufre importantes cambios: existen delegaciones como Cuauhtémoc, Coyoacán e Iztapalapa, y municipios como Nezahualcóyotl, Ixtapaluca y Chalco con Ageb de alta concentración de establecimientos industriales en zonas designadas para otros usos, que son principalmente habitacionales mixtos o habitacionales con comercio. Cabe mencionar que nuevamente se encontraron demarcaciones como Azcapotzalco, Cuautitlán Izcalli, Tlalnepantla y Ecatepec que en sus zonas industriales autorizadas se concentran las Ageb con mayor cantidad de establecimientos.

Al momento de revisar el cuadro 3, donde se compara la actividad económica registrada en 2003 con los planes y programas de desarrollo urbano aprobados a partir de 1997, se notó un comportamiento similar al periodo anterior. Proporcionalmente, existe un alto porcentaje de establecimientos industriales localizados fuera de las zonas autorizadas, pero las 5260 ubicadas en uso de suelo industrial permitido, que representaban $11,5 \%$, concentraban casi $42 \%$ de la población ocupada y $62 \%$ de la producción manufacturera.

Las empresas establecidas en suelo autorizado para la industria siguen siendo más grandes en cuanto a personal ocupado. Por un lado, se tienen las fábricas fuera de zonas industriales autorizadas con menos de 11 trabajadores por establecimiento, y por el otro, unidades económicas casi seis veces más grandes al emplear a más de 60 personas en promedio por fábrica en suelo industrial permitido. Respecto a la producción por establecimiento, la diferencia se incrementa entre las unidades económicas ubicadas dentro y fuera de zonas industriales autorizadas. Mientras que en el caso de los establecimientos censados en 1993 la diferencia era de casi siete veces, para 2003, la producción por fábrica en uso de suelo industrial fue 12 veces mayor.

En cuanto a las diferencias entre los establecimientos del Distrito Federal y de los municipios ubicados en suelo industrial permitido se redujeron. Es posible observar una mayor similitud en cuanto a su tamańo y su producción respecto al periodo de análisis anterior. Referente al personal ocupado, 62 y 58 empleados por unidad económica promedian los establecimientos del Distrito Federal y de los municipios conurbados, respectivamente. Algo similar ocurre en cuanto a la producción, donde para el caso de las fábricas ubicadas en las delegaciones es de 19,000,000 de pesos mientras que para las correspondientes a los municipios conurbados es de 17,600,000 de pesos. 


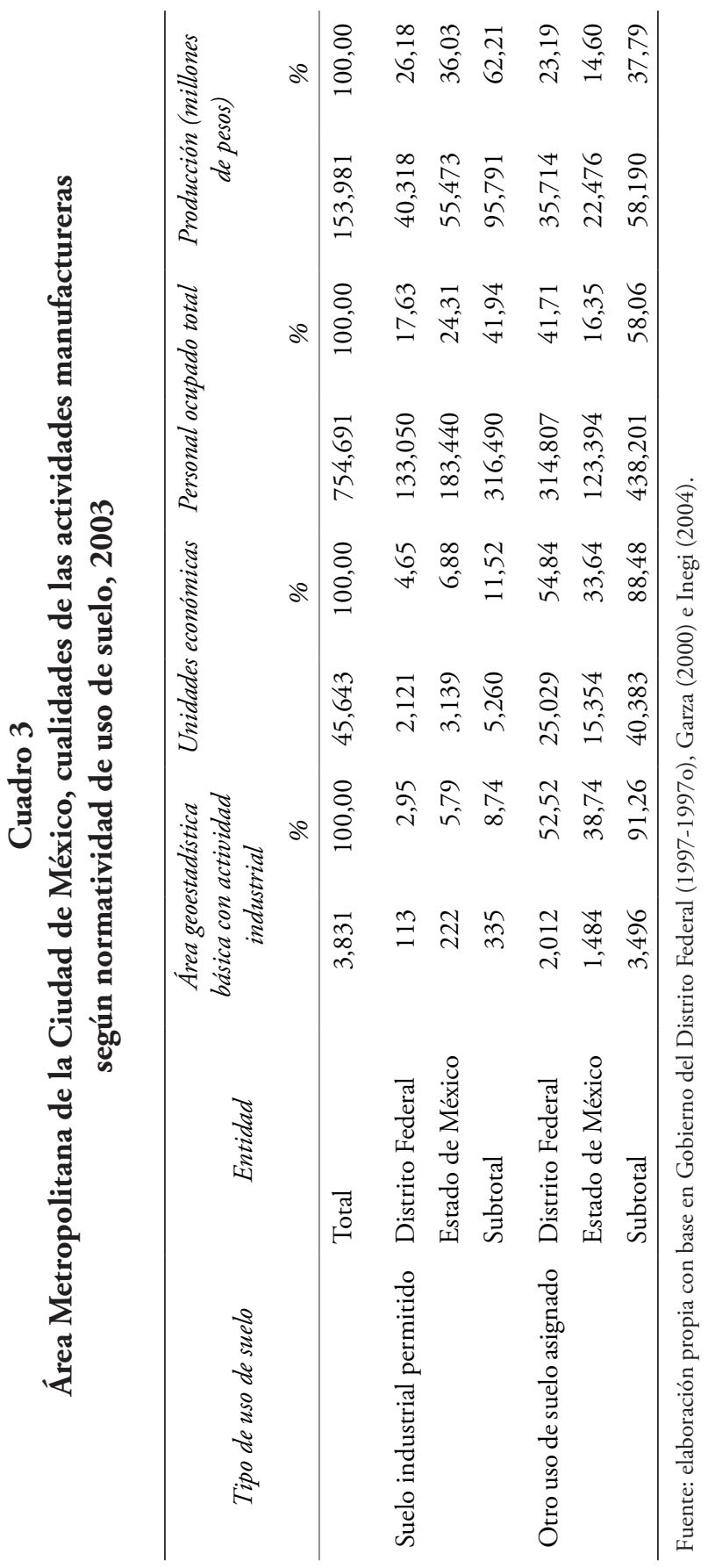


La política de descentralización de la actividad industrial implementada desde la década de los ochenta, si bien ha ocasionado la disminución de suelo asignado para esta actividad en el Distrito Federal, también ha causado que más establecimientos se emplacen en otro tipo de uso de suelo, agudizando la irregularidad en la ciudad. Mientras que en 1993 casi $58 \%$ de las unidades industriales con irregularidad de uso de suelo se localizaba en las delegaciones, para 2003 se había incrementado a casi 62 por ciento.

A pesar de la dispersión de los establecimientos industriales, pues 75\% de las Ageb registraron alguna actividad manufacturera, se encontraron zonas en las que se asignaron usos de suelo industrial pero que no se emplazaron unidad económica. En 1993, 11 Ageb con uso industrial asignado no tenían registrada actividad manufacturera, para 2003 sucede algo similar, pues 13 Ageb destinadas para uso industrial no registraron actividad de este tipo. Esto puede ser reflejo de la carencia técnica y metodológica de quienes elaboran los planes y programas de desarrollo urbano, al no considerar los criterios de localización del sector industrial para la designación de los usos de suelo, por lo que destinan zonas no atractivas para que los empresarios establezcan sus fábricas.

\subsection{Regularización versus regulación del uso de suelo industrial}

De manera intuitiva se han elaborado argumentos sobre el papel de la planeación urbana, cuya función se ha orientado más hacia la regularización de actividades existentes en vez de orientar el funcionamiento y dinámica de la estructura urbana. De tal forma, se esperaría que los planes y programas de desarrollo urbano, en lugar de influir en la localización de las unidades económicas del futuro, se asemejen más a la distribución espacial de la actividad industrial del pasado, reconociendo las zonas con alta concentración de establecimientos. Sin embargo, este fenómeno no es tan evidente como se esperaría, ya que el mapa 5, que describe el nivel de concentración de las unidades económicas en 1993, no corresponde con la asignación normativa de uso de suelo industrial aprobado en 1997.

El resultado del análisis de los cuadros anteriores, donde se mostró que la mayoría de la producción del sector manufacturero se localizaba en zonas industriales autorizadas, orientó a comparar la distribución espacial de esta variable levantada en 1993 (mapa 7) y se llegó a una destacada coincidencia con lo dispuesto en los planes y programas de 1997 mostrados en el mapa 3. Esta correspondencia orienta a pensar que no necesariamente se regularizan las zonas industriales que concentran una gran cantidad de establecimientos, sino las que alcanzan altos niveles de 


\section{Mapa 7}

Área Metropolitana de la Ciudad de México, distribución de la

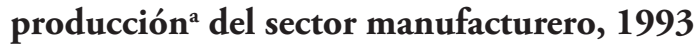

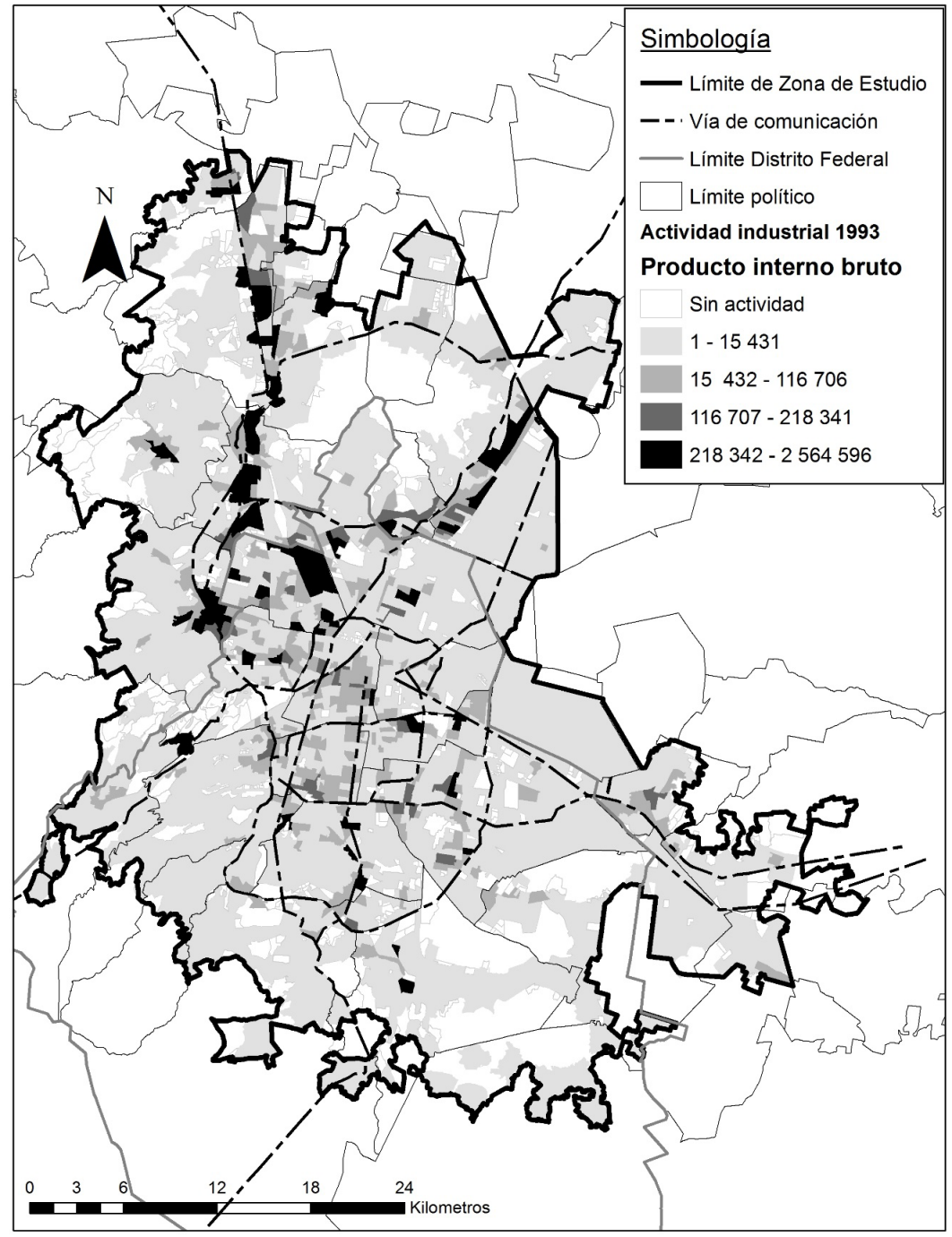

Fuente: elaboración propia con base en los datos del XIV Censo Industrial, 1994, (Inegi, 1994).

a Los datos están presentados en miles de pesos corrientes. 


\section{Mapa 8}

Área Metropolitana de la Ciudad de México: distribución de la producción $^{\text {a }}$ del sector manufacturero, 2003

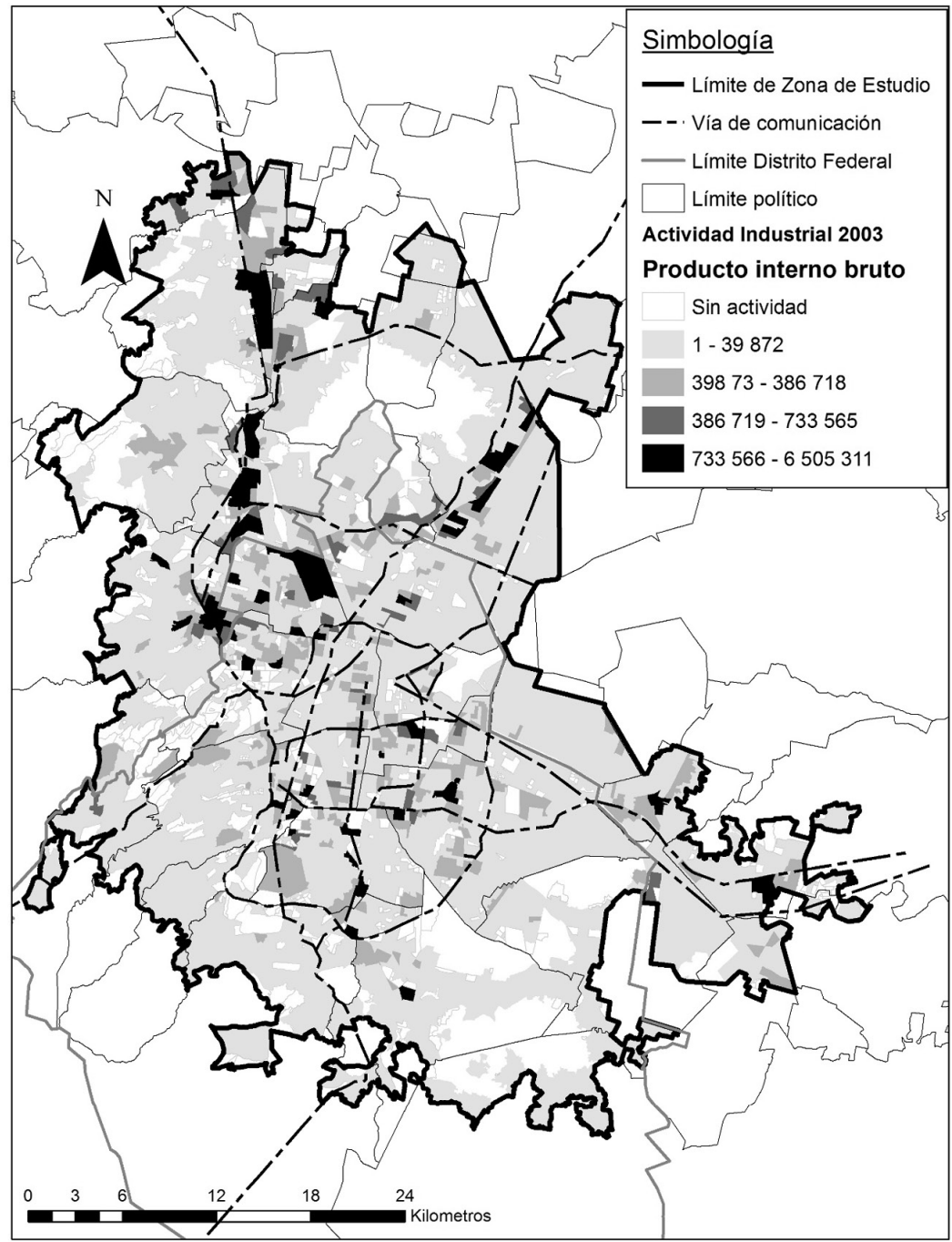

Fuente: elaboración propia con base en los datos del XVI Censo Industrial, 2004 (Inegi, 2004). ${ }^{a}$ Los datos están presentados en miles de pesos corrientes. 
producción; destacan municipios como Tlalnepantla, Ecatepec, Cuautitlán Izcalli y La Paz donde se modificaron y crearon zonas con uso de suelo industrial en lugares donde las empresas ya tenían alta producción.

Algo similar sucedió, aunque de forma más sutil, al revisar la distribución espacial de la producción industrial del 2003 expuesta en el mapa 8, al contrastar esta información con lo dispuesto en los programas y planes vigentes hasta la fecha, lo cual se observa en el mapa 4. Si bien no hay modificaciones significativas en cuanto a la organización espacial de la producción industrial en la ciudad, sí se perciben nuevos reconocimientos por parte de las autoridades locales a zonas industriales con relativa importancia productiva. Tultitlán amplía sus zonas industriales, resultado del incremento del valor agregado por establecimiento. En Iztacalco y en los municipios de Atizapán de Zaragoza, La Paz y Chalco se reconocen zonas industriales que ya se registraban desde 1993, pero que no tenían un destacado nivel de producción; fue hasta sus últimos planes municipales de desarrollo urbano que decidieron ampliar sus zonas con uso industrial permisible.

Algo diferente ocurre en Tlalnepantla y Ecatepec, donde se conservan las zonas con alta producción industrial, pero a pesar de ello ya no se les asigna el uso industrial. Estos cambios, para el caso de Ecatepec contradicen lo dispuesto en el Plan de Desarrollo Urbano del Estado de México citado en el mismo Plan de Desarrollo Urbano de dicho municipio, donde se menciona que se debe impulsar del desarrollo industrial en el eje México-Pachuca (Secretaría de Desarrollo Urbano del Estado de México, 2003c: 70). En contraste, el Plan Municipal de Desarrollo Urbano de Tlalnepantla justifica esta reducción de áreas de uso de suelo industrial bajo el argumento dispuesto en el Plan de Desarrollo Urbano del Estado de México del 2008 al respecto de que las zonas industriales ya presentan problemas de funcionamiento (Secretaría de Desarrollo Urbano del Estado de México, 2008: 56). Adicionalmente menciona que se está observando un proceso de emigración de los establecimientos industriales de la zona central del municipio.

\section{Conclusiones}

Es un hecho que la influencia del gobierno en la localización industrial a partir de la asignación de usos del suelo es muy limitada. En lugar de regular los planes y programas de desarrollo urbano termina reconociendo los conglomerados de establecimientos con alta productividad. Esto es, se asigna el uso de suelo a zonas donde las grandes empresas alcanzan una producción anual alta y aquellas zonas de alta concentración de es- 
tablecimientos medianos que en suma logran una producción digna de ser reconocida.

En contraparte, una gran cantidad de pequeñas unidades económicas dedicadas a la manufactura no obtienen la regularización por su baja productividad, a pesar de tener en ocasiones un destacado nivel de concentración espacial. Sin embargo, estas unidades económicas tampoco son cerradas, ya que con el pasar de los años es posible registrar una constante dispersión de pequeños establecimientos en toda el AMCM.

Este análisis permite observar un fenómeno dual en el que las grandes y medianas empresas, que concentran cada vez más la producción, tienen la fuerza económica para influir políticamente en las decisiones sobre la definición de usos de suelo; mientras que las pequeñas y microempresas, dispersas o concentradas, deben operar casi en la clandestinidad en zonas donde su actividad industrial es considerada ilegal en cuanto al uso de suelo. Estas últimas empresas se caracterizan por tener una participación cada vez más baja en la producción y personal ocupado a escala metropolitana.

Estas cualidades expresan la existencia de un Estado no intervencionista, cuya capacidad de ordenamiento territorial no es correctamente ejercida. La política de regularización y corrección a posteriori destaca ante el hecho de que los empresarios con suficiente capacidad económica y productiva ejercen presión para que sus establecimientos sean reconocidos y, como consecuencia, sea modificado el uso de suelo; es decir, en el área de estudio los gobiernos locales no son capaces de orientar correctamente el crecimiento urbano y terminan corrigiendo y reconociendo dinámicas urbanas externas. Además se enfrentan a una falta de coordinación entre sí y con los gobiernos del Estado de México y el Distrito Federal a fin de generar un ordenamiento integral del espacio urbano.

Bajo el contexto neoliberal se espera que el estado mantenga su política de no intervención, por lo que la designación de uso de suelo industrial para futuras zonas fabriles será muy limitada. Actualmente, el impulso para el crecimiento manufacturero a través de la creación de espacios públicos para el fomento de la actividad se limita a tres futuros parques de alta tecnología localizados en Iztapalapa ${ }^{6}$, Tláhuac ${ }^{7}$ y Atizapán de Zaragoza ${ }^{8}$ (Grupo Fidalex, 2011). Esto implica que prácticamente toda nueva industria que no se asiente en zonas industriales consolidadas o en estas tres nuevas alternativas deberá pasar por un proceso de regularización,

\footnotetext{
${ }^{6} \mathrm{Al}$ norte de la Central de Abastos se tiene el proyecto del Parque Industrial de Alta Tecnología "Cabeza de Juárez".

${ }^{7}$ Sobre a avenida Ferrocarril "San Lorenzo", el gobierno del Distrito Federal tiene proyectada la construcción del Parque Industrial de Alta Tecnología "Zapotitlán-Tláhuac".

${ }^{8} \mathrm{La}$ oferta de suelo industrial en los municipios conurbados es el Parque Tecnopolo "Esmeralda Bicentenario", ubicado sobre el libramiento vial Chamapa-Lechería.
} 
siempre y cuando su producción sea lo suficientemente alta como para tener capacidad de ejercer presión política.

Cabe mencionar que los actuales proyectos de parques industriales de alta tecnología no se ubican en las zonas predominantemente industriales y con mayor dinamismo de crecimiento. Esta condición pone en duda la capacidad técnica por parte de los planificadores ante el fenómeno de crecimiento industrial de la ciudad. Se observa una falta de visión para fomentar la construcción de nuevas zonas industriales con tecnología en zonas atractivas para el emplazamiento de nuevos establecimientos fabriles con procesos productivos altamente tecnificados.

Actualmente, el papel del estado ante la distribución espacial de la industria no es tanto la localización de los nuevos establecimientos, sino la consolidación, crecimiento y sobre todo radicalización de permanencia de los establecimientos fabriles en polígonos ya creados. Esto determina y enfatiza la importancia de las actuales zonas manufactureras, pues la ausencia de nuevas zonas industriales factibles y el complejo proceso de regularización dificultan aún más que las empresas ya establecidas decidan trasladar sus instalaciones a una nueva zona que les pudiese brindar un mejor potencial de crecimiento y mayor beneficio económico, por lo que se podría afirmar que el mismo Estado coadyuva a la actual tendencia hacia la divergencia entre zonas con alta y baja intensidad industrial. La factibilidad normativa se ve limitada a tres parques industriales públicos o a la oferta privada.

Evidentemente, la falta de iniciativa de las múltiples instituciones públicas encargadas en la planificación de la ciudad representa una incertidumbre jurídica, pues las empresas al observar una ausencia de suelo autorizado para la instalación de sus fábricas, lo consideran un riesgo para su inversión, esto impacta negativamente la competitividad de la ciudad al no otorgar certeza legal a las nuevas empresas o las obliga a conocer los mecanismos políticos de negociación extraoficiales para obtener el permiso de uso de suelo.

El desconocimiento de los requerimientos de localización industrial llevó a crear diagnósticos inadecuados y a proponer acciones que no responden a las necesidades de este sector. Las nuevas zonas, pese a que en algunas de ellas se realizaron estudios de factibilidad, no tuvieron el éxito esperado, ${ }^{9}$ lo que denota otro ejemplo de deficiencia técnica al momento de realizar la planificación urbana.

Aunado a lo anterior, la coordinación de las diferentes instancias de gobierno vinculadas con la planeación territorial de toda el área metro-

\footnotetext{
${ }^{9}$ Garza (1992) en su texto Desconcentración tecnológica y localización industrial en México aborda este tema, evidenciando todas las deficiencias que tuvieron estos proyectos inmobiliarios de corte estatal.
} 
politana es fundamental para que se pueda lograr un proceso de urbanización adecuado y ordenado. Esto obliga a evaluar la capacidad administrativa como factor trascendental en la eficiencia de la política pública. En el AMCM, cuya extensión territorial ha involucrado en la planeación urbana a una gran cantidad de gobiernos locales, dos estatales y el federal, se han realizado diversos intentos por coordinar las innumerables dependencias que están de una u otra forma vinculadas con la tarea de la planeación física. En ese sentido, es sustancial que se elaboren programas metropolitanos de desarrollo urbano con validez jurídica que determine una política pública común en temas urbanos y que funja como parámetro para la realización de los programas delegacionales y municipales.

Es imperativa la necesidad de construir un cuerpo normativo adecuado a la actual política neoliberal asumida por el Estado mexicano. El conjunto de leyes que actualmente rigen la actividad de planeación y planificación urbana no ha sido capaz de lograr una regulación eficaz de las actividades urbanas, entre ellas la manufacturera, que durante todo el siglo XX se distribuyó en función de sus requerimientos empresariales y, a excepción de algunos proyectos exitosos como el Parque Vallejo, la capacidad de ordenamiento territorial de la industria ha sido nula. Ante la nueva visión neoliberal es necesario construir un sistema de planeación urbana eficiente que responda a las nuevas exigencias y el papel que las ciudades tienen en el contexto global.

Es innegable la importancia que tiene el Estado en la organización espacial de las ciudades; evadir dicho rol crea el riesgo de negar una de las contradicciones principales del sistema capitalista relacionada con la socialización de las fuerzas productivas. Limitar el papel del Estado en la configuración espacial industrial intraurbana contrae el riesgo de dejar a las ciudades mexicanas a la zaga en la competitividad mundial. El papel del Estado es fundamental para que las empresas decidan emplazarse en una ciudad cuya organización espacial le brindará ventajas para hacer más eficientes sus procesos de producción.

\section{Fuentes consultadas}

Alonso, William (1960), "A theory of the urban land market", Papers in Regional Science Association, 6 (1), John Wiley \& Sons Inc., Azores, pp. 149-157.

Babcock, Richard (1995), “The purpose of zoning”, en Jay Stein (ed.), Classic readings in urban planning, an introductions, McGraw-Hill, Nueva York, pp. 133-139. 
Caves, Roger (2005), Encyclopedia of the city, Routledge, Nueva York.

Cruz-Muñoz, Fermín Alí y Gustavo Garza (2014), "Configuración microespacial de la industria en la Ciudad de México a inicios del siglo XXI", Revista de Estudios Demográficos y Urbanos, 29 (1), El Colegio de México, México, pp. 9-52.

Cruz-Muñoz, Fermín Alí (2012), "Configuración espacial de la industria en la Ciudad de México", tesis doctoral, El Colegio de México, México.

Dirección General de Reordenación Urbana y Protección Ecológica (1987), Programa General de Desarrollo Urbano del Distrito Federal, 1987-1988, Departamento del Distrito Federal, México.

Feagin, Joe (1990), Building American cities the urban real estate game, Prentice-Hall, Nueva Jersey.

Fuente, María (1999), Diccionario de historia urbana y urbanismo. El lenguaje de la ciudad en el tiempo, Universidad de Carlos III de Madrid, Madrid.

Garza, Gustavo (2000), Ciudad de México en el fin del segundo milenio, El Colegio de México, México.

Garza, Gustavo (1998), "Normatividad urbanística virtual en la ciudad de México", en Gustavo Garza y Fernando Rodríguez (eds.), Normatividad urbanistica en las principales metrópolis de México, El Colegio de México, México, pp. 89-142.

Garza, Gustavo (1992), Desconcentración, tecnología, y localización industrial en México los parques y ciudades industriales, 1953-1988, El Colegio de México, México.

Garza, Gustavo (comp.) (1987), Atlas de la Ciudad de México, El Colegio de México-Departamento del Distrito Federal, México.

Gleeson, Brendan y Nicolas Low (2000), "Revaluating planning: rolling back neo-liberalism in Australia”, Progress in Planning, 53 (2), Elservier, London, pp. 83-164. 
Gleeson, Brendan y Kerry Grundy (1997), "New Zealand's planning revolution five years on: a preliminary assessment", Journal of Environmental Planning and Management, 40 (3), University of Newcastle, Newcastle, pp. 293-313.

Gobierno del Distrito Federal (2008), Programa delegacional de desarrollo urbano de Azcapotzalco, Gaceta oficial del Distrito Federal, Distrito Federal.

Gobierno del Distrito Federal (2008a), Programa delegacional de desarrollo urbano de Cuauhtémoc, Gaceta oficial del Distrito Federal, Distrito Federal.

Gobierno del Distrito Federal (2008b), Programa delegacional de desarrollo urbano de Iztacalco, Gaceta oficial del Distrito Federal, Distrito Federal.

Gobierno del Distrito Federal (2008c), Programa delegacional de desarrollo urbano de Iztapalapa, Gaceta oficial del Distrito Federal, Distrito Federal.

Gobierno del Distrito Federal (2008d), Programa delegacional de desarrollo urbano de Miguel Hidalgo, Gaceta oficial del Distrito Federal, Distrito Federal.

Gobierno del Distrito Federal (2008e), Programa delegacional de desarrollo urbano de Tláhuac, Gaceta oficial del Distrito Federal, Distrito Federal.

Gobierno del Distrito Federal (2005), Programa delegacional de desarrollo urbano de Benito Juárez, Gaceta oficial del Distrito Federal, Distrito Federal.

Gobierno del Distrito Federal (2005a), Programa delegacional de desarrollo urbano de Magdalena Contreras, Gaceta oficial del Distrito Federal, Distrito Federal.

Gobierno del Distrito Federal (2005b), Programa delegacional de desarrollo urbano de Venustiano Carranza, Gaceta oficial del Distrito Federal, Distrito Federal. 
Gobierno del Distrito Federal (2005c), Programa delegacional de desarrollo urbano de Xochimilco, Gaceta oficial del Distrito Federal, Distrito Federal.

Gobierno del Distrito Federal (1997), Programa delegacional de desarrollo urbano de Álvaro Obregón, Gaceta oficial del Distrito Federal, Distrito Federal.

Gobierno del Distrito Federal (1997a), Programa delegacional de desarrollo urbano de Azcapotzalco, Gaceta oficial del Distrito Federal, Distrito Federal.

Gobierno del Distrito Federal (1997b), Programa delegacional de desarrollo urbano de Benito Juárez, Gaceta oficial del Distrito Federal, Distrito Federal.

Gobierno del Distrito Federal (1997c), Programa delegacional de desarrollo urbano de Coyoacán, Gaceta oficial del Distrito Federal, Distrito Federal.

Gobierno del Distrito Federal (1997d), Programa delegacional de desarrollo urbano de Cuajimalpa de Morelos, Gaceta oficial del Distrito Federal, Distrito Federal.

Gobierno del Distrito Federal (1997e), Programa delegacional de desarrollo urbano de Cuauhtémoc, Gaceta oficial del Distrito Federal, Distrito Federal.

Gobierno del Distrito Federal (1997f), Programa delegacional de desarrollo urbano de Gustavo A. Madero, Gaceta oficial del Distrito Federal, Distrito Federal.

Gobierno del Distrito Federal (1997g), Programa delegacional de desarrollo urbano de Iztacalco, Gaceta oficial del Distrito Federal, Distrito Federal.

Gobierno del Distrito Federal (1997h), Programa delegacional de desarrollo urbano de Iztapalapa, Gaceta oficial del Distrito Federal, Distrito Federal.

Gobierno del Distrito Federal (1997i), Programa delegacional de desarrollo urbano de Magdalena Contreras, Gaceta oficial del Distrito Federal, Distrito Federal. 
Gobierno del Distrito Federal (1997j), Programa delegacional de desarrollo urbano de Miguel Hidalgo, Gaceta oficial del Distrito Federal, Distrito Federal.

Gobierno del Distrito Federal (1997k), Programa delegacional de desarrollo urbano de Milpa Alta, Gaceta oficial del Distrito Federal, Distrito Federal.

Gobierno del Distrito Federal (1997l), Programa delegacional de desarrollo urbano de Tláhuac, Gaceta oficial del Distrito Federal, Distrito Federal.

Gobierno del Distrito Federal (1997m), Programa delegacional de desarrollo urbano de Tlalpan, Gaceta oficial del Distrito Federal, Distrito Federal.

Gobierno del Distrito Federal (1997n), Programa delegacional de desarrollo urbano de Venustiano Carranza, Gaceta oficial del Distrito Federal, Distrito Federal.

Gobierno del Distrito Federal (1997o), Programa delegacional de desarrollo urbano de Xochimilco, Gaceta oficial del Distrito Federal, Distrito Federal.

Gobierno del Estado de México (1985), Plan municipal de desarrollo urbano Chalco, Gobierno del Estado de México, Toluca.

Gobierno del Estado de México (1985a), Plan municipal de desarrollo urbano Nezahualcóyotl, Gobierno del Estado de México, Toluca.

Gobierno del Estado de México (1984), Plan municipal de desarrollo urbano Atizapán de Zaragoza, Gobierno del Estado, Toluca.

Gobierno del Estado de México (1984a), Plan municipal de desarrollo urbano Coacalco, Gobierno del Estado de México, Toluca.

Gobierno del Estado de México (1984b), Plan municipal de desarrollo urbano Cuautitlán, Gobierno del Estado de México, Toluca.

Gobierno del Estado de México (1984c), Plan municipal de desarrollo urbano Huixquilucan, Gobierno del Estado de México, Toluca. 
Gobierno del Estado de México (1984d), Plan municipal de desarrollo urbano Ixtapaluca, Gobierno del Estado de México, Toluca.

Gobierno del Estado de México (1984e), Plan municipal de desarrollo urbano La Paz, Gobierno del Estado de México, Toluca.

Gobierno del Estado de México (1984f), Plan municipal de desarrollo urbano Naucalpan de Juárez, Gobierno del Estado de México, Toluca.

Gobierno del Estado de México (1984g), Plan municipal de desarrollo urbano Tepotzotlán, Gobierno del Estado de México, Toluca.

Gobierno del Estado de México (1984h), Plan municipal de desarrollo urbano Tultitlán, Gobierno del Estado de México, Toluca.

Goxha, Venera (2014), "Development and changes in the industrial zone in Prizren", en International conference on Architecture and urban Design, Epoka University, Tirana, Albania, <http://dspace.epoka. edu.al/bitstream/handle/1/876/201.pdf?sequence=1>, 23 de junio de 2014.

Grupo Fidalex (2011), “Tecnoportal.com”, Grupo Fidalex, México, $<$ http://www.tecno-portal.com/front_content.php?idart=7930>, 16 de mayo de 2014.

Inegi (Instituto Nacional de Estadística y Geografía) (2004), XVI Censo industrial, Instituto Nacional de Estadística y Geografía, Aguascalientes.

Inegi (Instituto Nacional de Estadística y Geografía) (2004a), Delimitación de las zonas metropolitanas de México, Inegi-Conapo-Sedesol, México.

Inegi (Instituto Nacional de Estadística y Geografía) (1994), XIV Censo industrial, Instituto Nacional de Estadística y Geografía, Aguascalientes.

Iracheta, Alfonso (1997), Planeación y desarrollo, una visión del futuro, Plaza y Valdés, México. 
Li Tian y Tiyan Shen (2011), "Evaluation of plan implementation in the transitional China: a case of Guangzhou city master plan", Cities, núm. 28, Elsevier, Washington, pp. 11-27.

Peel, Deborah, Greg Lloyd y Alex Lord (2009), "Business improvement districts and the discourse of contractualism", European Planning Studies, 17 (3), Routledge Taylor \& Francis, Cardiff, pp. 401-422.

Real Estate, Market \& LifeStyle (2012), "Los 100 parques industriales generadores de empleos directos", La Guía Inmobiliaria de México: Real Estate Market \& Lifestyle, 2012 (86), Real Estate Group, pp. 56-57.

Sager, Tore (2011), "Neo-liberal urban planning policies: a literature survey 1990-2010”, Progress in Planning, núm. 76, Elsevier, Londres, pp. 147-199.

Sánchez, Gerardo (1999), La Ciudad de México en el periodo de las regencias, 1929-1997, Universidad Autónoma Metropolitana unidad Azcapotzalco, México.

Secretaría de Desarrollo Urbano del Estado de México (2009), Plan municipal de desarrollo urbano de Huixquilucan, Gobierno del Estado de México, Toluca.

Secretaría de Desarrollo Urbano del Estado de México (2009a), Plan municipal de desarrollo urbano de Cuautitlán Izcalli, Gobierno del Estado de México, Toluca.

Secretaría de Desarrollo Urbano del Estado de México (2009b), Plan municipal de desarrollo urbano de Chalco, Gobierno del Estado de México, Toluca.

Secretaría de Desarrollo Urbano del Estado de México (2009c), Plan municipal de desarrollo urbano de Ixtapaluca, Gobierno del Estado de México, Toluca.

Secretaría de Desarrollo Urbano del Estado de México (2008), Plan municipal de desarrollo urbano de Tlalnepantla de Baz, Gobierno del Estado de México, Toluca. 
Secretaría de Desarrollo Urbano del Estado de México (2007), Plan municipal de desarrollo urbano de Naucalpan de Juárez, Gobierno del Estado de México, Toluca.

Secretaría de Desarrollo Urbano del Estado de México (2005), Plan municipal de desarrollo urbano de Tepotzotlán, Gobierno del Estado de México, Toluca.

Secretaría de Desarrollo Urbano del Estado de México (2005a), Plan municipal de desarrollo urbano de Valle de Chalco, Gobierno del Estado de México, Toluca.

Secretaría de Desarrollo Urbano del Estado de México (2004), Plan municipal de desarrollo urbano de Ecatepec, Gobierno del Estado de México, Toluca.

Secretaría de Desarrollo Urbano del Estado de México (2004a), Plan municipal de desarrollo urbano de Nezahualcóyotl, Gobierno del Estado de México, Toluca.

Secretaría de Desarrollo Urbano del Estado de México (2003), Plan municipal de desarrollo urbano de Atizapán de Zaragoza, Gobierno del Estado de México, Toluca.

Secretaría de Desarrollo Urbano del Estado de México (2003a), Plan municipal de desarrollo urbano de Coacalco, Gobierno del Estado de México, Toluca.

Secretaría de Desarrollo Urbano del Estado de México (2003b), Plan municipal de desarrollo urbano de Tultitlán, Gobierno del Estado de México, Toluca.

Secretaría de Desarrollo Urbano del Estado de México (2003c), Plan municipal de desarrollo urbano de Ecatepec, Gobierno del Estado de México, Toluca.

Secretaría de Desarrollo Urbano del Estado de México (2003d), Plan municipal de desarrollo urbano de La Paz, Gobierno del Estado de México, Toluca.

Secretaría de Desarrollo Urbano y Vivienda (1996), Programa de desarrollo urbano del Distrito Federal, Comisión de Gobierno, México. 
Subsecretaría de Asentamientos Humanos (s/f), Términos más usuales sobre asentamientos humanos, Secretaría de Asentamientos $\mathrm{Hu}-$ manos y Obras Públicas, México.

Unesco (1987), Diccionario Unesco de ciencias sociales, Planeta-Agustini, Barcelona.

Webster, Donald (1958), Urban planning and municipal public policy, Harper, New York.

Yuan Meng, Feng Zhang, Ping An, Ma Dong, Zhao Wang y Tingting Zhao (2008), "Industrial land-use efficiency and planning in Shunyi, Beijing", Landscape and Urban Planning, núm. 85, Elsevier, Shanghai, pp. 40-48.

Zoido, Florencio, Sofía de la Vega, Guillermo Morales, Rafael Mas y Rubén Lois (2000), Diccionario de geografía urbana, urbanismo y ordenación del territorio, Ariel, Barcelona.

Recibido: 19 de mayo de 2014. Corregido: 17 de octubre de 2014. Aceptado: 29 de mayo de 2015.

Fermín Alí Cruz-Muñoz. Doctor en estudios urbanos y ambientales por El Colegio de México. Actualmente es profesor-investigador del Centro de Investigaciones Económicas, Administrativas y Sociales del Instituto Politécnico Nacional y profesor de asignatura de la Facultad de Arquitectura de la Universidad Nacional Autónoma de México. Las principales líneas de investigación son planeación urbana, localización intrametropolitana de la actividad económica y valuación inmobiliaria. Entre sus publicaciones destacan: "Configuración microespacial de la industria en la Ciudad de México a inicios del siglo XXI", Revista Estudios Demográficos y Urbanos, 29 (1), El Colegio de México, México, pp. 9-52 (2014); "Evolución de la distribución industrial en la Ciudad de México, 19852008", Cátedra de Investigación. Nuevo Urbanismo en México, 7 (11 y 12), Instituto Tecnológico de Estudios Superiores de Monterrey, Querétaro, pp. 38-50 (2013) y "La disposición de la industrial artesanal y fabril en la Ciudad de México durante el siglo XIX", Quaderni di Thule, Rivista italiana di studi americanistici, XI, Centro Studi Americanistici "Circolo Amerindiano" Onlus, Perugia, pp. 193-206 (2012). 